\title{
Analisis Karakteristik Konsumen Hotel " $X$ " dengan Menggunakan Metode K-Means Clustering
}

\author{
Taofik Hidayat ${ }^{1}$ dan Bramantiyo Eko Putro ${ }^{2 *}$ \\ 1,2 Teknik Industri Universitas Suryakancana \\ Jl. Pasir Gede Raya Cianjur \\ 1hidayattaofik31@gmail.com \\ 2*bramantiyo@unsur.ac.id
}

\section{Analysis Consumer Characteristics of Hotel "X" Using the K-Means Clustering Method}

Dikirimkan: 06, 2020. Diterima: 09, 2020. Dipublikasikan : 09, 2020.

\begin{abstract}
Hotel " $X$ " has a problem with a marketing strategy that is incompatible with the characteristics of consumers staying at the hotel " $X$ ". This is because the hotel " $X$ " does not yet know the characteristics of its consumers. The marketing strategy that is not optimal also affects the occupancy rate of the " $X$ " hotel. This problem can be seen from the fluctuating number of overnight stayers. So that the number of hotel visitors is small. The purpose of this study is to determine the marketing strategy that is following the characteristics of consumers in the hotel " $X$ ", using the K-means clustering method. The research data collection was done by collecting secondary data based on historical data of Hotel " $X$ ", which amounted to 725 transactions. The data collected is data on gender, room type, travel companions, length of stay, price, area of origin, booking method. Data processing using the k-means clustering method was carried out with the help of SPSS 20. The results of the analysis of the k-means clustering method were gender, type of room booked, number of friends, length of stay, room price ordered, nationality, booking method. This study obtained 3 clusters. The first cluster is a cluster that often books economical rooms and orders online called online-low customer. The second cluster is the medium customer, namely the consumer cluster that orders middle classrooms, and the 3rd cluster which is similar to the 1st cluster but ordering through media other than online, namely the offline-manual customer. Keywords - Consumer characteristic, Hotel, K-means clustering.
\end{abstract}

Abstrak- Hotel "X" memiliki permasalahan pada strategi pemasaran yang tidak sesuai dengan karakteristik konsumen yang menginap di hotel " $X$ ". Hal ini dikarenakan hotel " $X$ " belum mengetahui karakteristik konsumennya. Strategi pemasaran yang belum maksimal juga mempengaruhi tingkat okupansi hotel " $\mathrm{X}$ ". Permasalahan ini terlihat dari jumlah penginap selama 1 bulan yang fluktuatif. Sehingga jumlah pengujung hotel sedikit. Tujuan penelitian ini untuk mengetahui strategi pemasaran yang sesuai dengan karakteristik konsumen di hotel "X", dengan metode $K$-means clustering. Pengumpulan data penelitian dilakukan dengan cara mengumpulkan data sekunder berdasarkan data historis Hotel " $\mathrm{X}$ " yang berjumlah 725 transaksi. Data yang dikumpulkan adalah data jenis kelamin, tipe kamar, teman perjalanan, lama menginap, harga, asal daerah, metode booking. Pengolahan data dengan metode $k$-means clustering dilakukan dengan bantuan SPSS 20. Hasil analisis dari metode $k$-means clustering faktor yang berpengaruh adalah jenis kelamin, tipe kamar yang dipesan, jumlah teman, lama menginap, harga kamar yang di pesan, kewarganegaraan, metode booking. Penelitian ini memperoleh 3 cluster. Cluster pertama merupakan cluster yang sering memesan kamar ekonomis dan memesan secara daring disebut online-low customer. Cluster ke-2 bernama medium customer yaitu cluster konsumen yang memesan kamar kelas menengah, dan cluster ke-3 yang mirip dengan cluster ke-1 tapi memesan melalui media selain daring yaitu offline-manual customer. Kata kunci - Karakteristik konsumen, Hotel, K-means clustering.

\section{PENDAHULUAN}

Pada era globalisasi sektor pariwisata merupakan sektor yang terus berkembang dan sangat diperhatikan karena memberikan peluang usaha bagi siapa saja yang terlibat di dalamnya. Industri pariwisata merupakan industri andalan di kota Bandung yang berkontribusi secara signifikan 
terhadap perekonomian. Data menunjukkan bahwa pariwisata merupakan penyumbang terbesar. Baik yang berasal dari perhotelan, tempat hiburan dan kafe. Kepala Dinas Kebudayaan dan Pariwisata Kota Bandung Kenny Dewi Kaniasari menjelaskan bahwa industri pariwisata yang menyumbangkan Rp. 659.226.500.992 atau sebesar 30,31\% dari total pendapatan pajak daerah Rp2.174.863.780.863 dengan total nilai investasi sektor pariwisata di tahun 2017 sebesar Rp. 276.306.114.860 mengalami peningkatan dari tahun 2013 hingga 2018 . Di mana penginapan menyumbang $7,54 \%$, restoran $13,08 \%$, jumlah kenaikan tempat hiburan $17,29 \%, 101,89$ persen dari kenaikan biro perjalanan wisata serta 152,08\% dari kenaikan jumlah jasa usaha Meeting, Incentive, Convention, Exhibition [1].

Hotel " $X$ " adalah salah satu hotel bintang 3 yang terletak di kawasan Jalan Setiabudi Bandung, Jawa Barat memiliki fasilitas seperti internet atau WIFI gratis yang tersedia di kamar, resepsionis 24 jam, restoran, kolam renang dan pusat kesehatan. Hotel "X" memiliki konsep wisata yang memberikan layanan dan fasilitas yang halal salah satunya adalah hotel berkonsep islami dan memberikan layanan spesial bagi kaum muslim. Tidak hanya desainnya yang mengusung konsep syariah, para petugas hotel ini pun seluruhnya menggunakan busana konsep islami dan wajib bisa mengaji serta setiap minggu karyawan Hotel " $X$ " wajib mengaji bersama di masjid. Tamu hotel yang baru cek in akan mendapatkan welcome drink berupa air zamzam dan kurma, sehingga tampak berbeda dari hotel lainnya.

Terdapat beberapa permasalahan dari strategi pemasaran yang telah dilakukan. Promosi berupa diskon yang dilakukan oleh Hotel " $\mathrm{X}$ " masih sedikit konsumen yang berpartisipasi. Hal ini dikarenakan hotel "X" belum mengetahui karakteristik konsumen, strategi pemasaran yang belum maksimal, juga mempengaruhi tingkat okupansi hotel " $X$ ". Hal ini terlihat dari jumlah penginap selama 1 bulan yang fluktuatif pada Gambar 1.

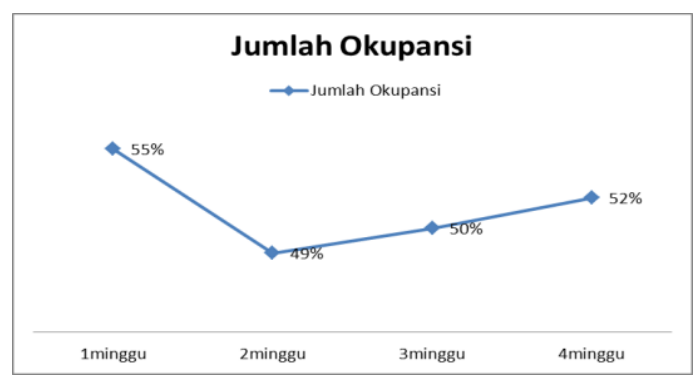

Gambar 1. Data Okupansi
Berdasarkan hal tersebut maka Hotel " $\mathrm{X}$ " memerlukan penggalian informasi dari tumpukantumpukan data yang berguna. Penggalian data berkaitan dengan pengungkapan pengetahuan mengenai data yaitu dengan clustering sebagai metode yang paling dalam mencari pola yang menarik dari data [2]. Clustering atau klasifikasi adalah metode yang digunakan untuk membagi rangkaian data menjadi beberapa grup berdasarkan kesamaan-kesamaan yang telah ditentukan sebelumnya [3]. Oleh karena itu penelitian ini bertujuan mengetahui faktor pertimbangan dalam melakukan clustering konsumen dan mengetahui cluster profil konsumen Hotel " $\mathrm{X}$ " yang terbentuk metode $K$-means Clustering.

\section{METOdologi Penelitian}

Penelitian ini menggunakan jenis dan sumber data primer dan sekunder. Data Primer diperoleh data pada hotel " $X$ konsumen hotel " $X$ " berserta lainnya. Data sekunder diperoleh data pengunjung dari Hotel "X" adalah Jenis Kelamin, Tipe Kamar, Teman Perjalanan, Lama Menginap, Harga, Asal Daerah, Metode Booking. Jumlah data sekunder yang diperoleh adalah 725 transaksi.

Pada pengolahan data terdapat beberapa tahapan. Pra proses data dilakukan pemrosesan data mentah untuk menyesuaikan kebutuhan. Pra proses data ini akan melakukan pemilihan atribut, membersihkan baris data yang memiliki nilai kosong, menggabungkan data mentah yang diperoleh, mencari data yang missing value [4].

Data yang telah bersih dilakukan clustering. Proses clustering dilakukan dengan alat bantu aplikasi SPSS versi 20. Akan diolah terlebih dahulu sebagai proses menentukan nilai $\mathrm{k}$ kemudian melakukan clustering dengan K-Means. perusahaan dalam mengelompokkan karakteristik konsumen.

Tahap pertama bertujuan untuk membantu penentuan nilai $\mathrm{k}$ sebagai masukan dalam penerapan K-Means. Proses clustering K-Means dilakukan untuk menemukan karakteristik konsumen yang dimiliki oleh Hotel " $\mathrm{X}$ ". Masukan proses K-Means lalu, penentuan nilai center dan jarak setiap objek data ke center. Sehingga keluarannya berupa cluster dengan memiliki center yang telah tetap atau tidak berpindah [5].

Proses verifikasi yang dilakukan untuk memastikan bahwa setiap konsumen yang dikelompokkan tepat berada dalam pengelompokan karakteristik tersebut, tahapan ini dilakukan dengan menghitung jarak ke titik pusat kelompok. Tahapan tersebut dilanjutkan dengan menguji performansi hasil cluster untuk mengukur tingkat performa model cluster yang telah terbentuk pada tahap sebelumnya. Pada uji 
performa ini akan mengetahui seberapa baik cluster dipisahkan dan dikelompokkan. Hasil olah data dianalisis serta dilakukan pembahasan mengenai perancangan yang telah dibuat.

\section{HASIL PENELITIAN}

\section{A. Pengumpulan Data}

Pada pengumpulan data, data diperoleh dari pengujian yang telah dilakukan selama 1 bulan di hotel "X" dari Tanggal/Bulan 16-September sampai 15-Oktober 2018. Tabel I menunjukkan sebagian data tersebut yaitu untuk data tanggal 20 September.

TABEL I

IN HOUSE GUEST REPORT 20SEPTEMBER 2018

\begin{tabular}{|c|c|c|c|c|c|c|c|}
\hline $\mathrm{N} 10$ & Jesis Kelanin & Tre Kamar & Iman & Irma Nengring & Hypa & Asel Dianh & Nende Boling \\
\hline 1 & Perempon & 157 & 2 & 2 & on:0,0.0. & $\mathrm{NA}$ & CANAMONHOTEL \\
\hline 2 & Perempun & CDLX & 4 & 3 & 861,00000 & $\mathbb{N A}$ & $A C O D A$ \\
\hline 3 & Lavidid & $D L X X$ & 2 & 2 & $60,000.0$ & $\mathrm{NA}$ & PADPRO \\
\hline 4 & Preatrian & DLXK & 2 & 2 & $60,0,0.0$ & $\mathbb{N A}$ & PADPRO \\
\hline 5 & Latibliti & CDLX & 3 & 517 & . & $\mathbb{N A}$ & CANA1ONHOFEL \\
\hline 6 & Preargum & CDLS & 4 & 4 & 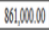 & SN & ACODA \\
\hline 1 & Perenguan & CDLS & 2 & 2 & $60,0,0,0$ & $\mathbb{N A}$ & PADPRO \\
\hline 8 & Labilatis & $15 !$ & 2 & 2 & $600,0,0.0$ & $\mathbb{N A}$ & CANA1ONHOFEL \\
\hline 9 & Prempon & DLXX & 2 & 2 & $60,0,0.0$ & $\mathbb{N A}$ & CANAMONHOTEL \\
\hline 10 & 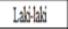 & DLXK & 2 & 3 & $600,000.00$ & $\mathrm{NA}$ & TRAVEOKA \\
\hline 11 & Labilatis & DLXI & 2 & $?$ & $60,0,0.0$ & IVI & TRAVEOKA \\
\hline 12 & Premplum & EXCE & 2 & 1 & 600,0000 & $\mathrm{NA}$ & mbith \\
\hline 13 & Prementan & $D L X X$ & 2 & 2 & 6000000 & $\mathrm{NA}$ & writith \\
\hline 14 & Levilatij & $\operatorname{coDS}$ & 4 & 2 & 9000000 & SN & ACODA \\
\hline 15 & Laiblati & CDLS & 2 & 3 & monowon & $\mathrm{NA}$ & mbith \\
\hline 16 & Perenovian & DOXK & 2 & 1 & 600,0000 & $\mathbb{N A}$ & CANAMONHOFE \\
\hline 17 & Latailidai & oxt & 3 & 2 & 800000000 & $\mathbb{N A}$ & CANANONHOTEL \\
\hline 18 & Lakilitaki & oxt & 2 & 2 & 600,00000 & $\mathrm{NA}$ & TRAELOKA \\
\hline 19 & Lakil-1dai & coox & 2 & 1 & 60000000 & $\mathbb{N A}$ & RAVELOKA \\
\hline
\end{tabular}

\section{B. Pra Processing Data}

Pada tahap ini akan dilakukan pemrosesan data mentah untuk menyesuaikan kebutuhan. Pra proses data ini dari mulai memeriksa data dan mencari data yang missing value, data outlier setelah itu data tersebut dinormalisasikan. Pada proses ini berupa data yang siap untuk clustering.

1) Missing value

Pada tahap ini akan dilakukan pengecekan keseluruhan data apakah terdapat missing value. Hal ini perlu dilakukan karena missing value dapat menyebabkan dalam perhitungan tidak efektif. Terlihat dari data di bawah ini Tabel II menunjukkan terdapat data missing value.
Jurnal Media

Teknik dan

Sistem Industri

TABEL II

DATA MISSING VALUE 20 SEPTEMBER 2018

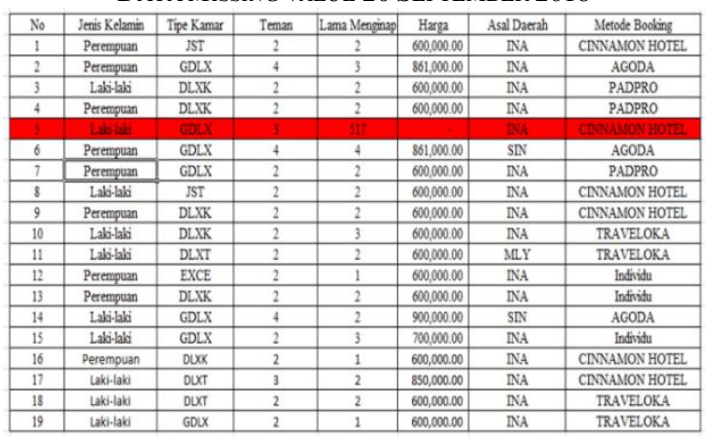

Terlihat dari Tabel II data missing value ditemukan pada record data pada nomor 5 di tanggal 20 September 2018 yang missing value yang ditemukan merupakan data harga kamar yang muncul atau tidak ada harga. Oleh karena itu perlakuan terhadap missing value tersebut dari record data dan tidak dilanjutkan dalam pengolahan data lebih lanjut.

\section{2) Data Outlier}

Pada tahap ini dilakukan pencarian data outlier, Sebagian hasil pencarian dapat dilihat pada Tabel III dan Gambar 2 yaitu histogram jenis kelamin.

TABEL III

PERHITUNGAN OUTLIER

\begin{tabular}{|c|c|c|c|c|c|c|c|c|}
\hline & & $\begin{array}{c}\text { Jenis } \\
\text { kelamin }\end{array}$ & Tipe kamar & Teman & $\begin{array}{c}\text { Lama } \\
\text { menginap }\end{array}$ & Asal daerah & Harga & $\begin{array}{l}\text { Metode } \\
\text { booking }\end{array}$ \\
\hline \multirow[t]{2}{*}{$\mathrm{N}$} & Valid & 725 & 725 & 725 & 725 & 725 & 725 & 725 \\
\hline & Missing & 0 & 0 & 0 & 0 & 0 & 0 & \\
\hline Mean & & 1.3283 & 2.5324 & 2.0717 & 2.2979 & 1.0786 & 677687.5 & 3.0883 \\
\hline \multicolumn{2}{|c|}{ Std. Error of Mean } & 0.01745 & 0.0455 & 0.02384 & 0.03212 & 0.01159 & | 5932.256 & 0.06527 \\
\hline Median & & 1 & 3 & 2 & 2 & 1 & 600000 & \\
\hline Mode & & 1 & 3 & 2 & 2 & 1 & 600000 & 1 \\
\hline Std. Deviation & & 0.46991 & 1.22502 & 0.64185 & 0.86495 & 0.31209 & \begin{tabular}{|l|}
$\mid 159730.9$ \\
\end{tabular} & 1.75752 \\
\hline Variance & & 0.221 & 1.501 & .412 & 0.748 & 0.097 & $2.55 E+10$ & 3.089 \\
\hline Skewness & & 0.733 & 0.646 & 1.632 & 0.798 & 4.284 & 0.842 & 0.487 \\
\hline \multicolumn{2}{|c|}{ Std. Error of Skewness } & 0.091 & 0.091 & 0.091 & 0.091 & 0.091 & 0.091 & 0.091 \\
\hline Kurtosis & & -1.467 & 0.347 & 4.368 & 1.257 & 19.124 & 0.781 & -0.844 \\
\hline \multicolumn{2}{|c|}{ Std. Error of Kurtosis } & 0.181 & 0.181 & 0.181 & 0.181 & 0.181 & 0.181 & 0.181 \\
\hline Range & & 1 & 5 & 4 & 5 & 2 & 897211 & 6 \\
\hline Minimum & & 1 & 1 & 1 & 1 & 1 & 402789 & 1 \\
\hline Maximum & & 2 & 6 & 5 & 6 & 3 & 1300000 & \\
\hline Sum & & 963 & 1836 & 1502 & 1666 & 782 & $4.91 E+08$ & 2239 \\
\hline \multirow[t]{3}{*}{ Percentiles } & 25 & 1 & 1 & 2 & 2 & 1 & 600000 & 1 \\
\hline & 50 & 1 & 3 & 2 & 2 & 1 & 600000 & \\
\hline & 75 & 2 & 3 & 2 & 3 & 1 & 827925 & \\
\hline
\end{tabular}




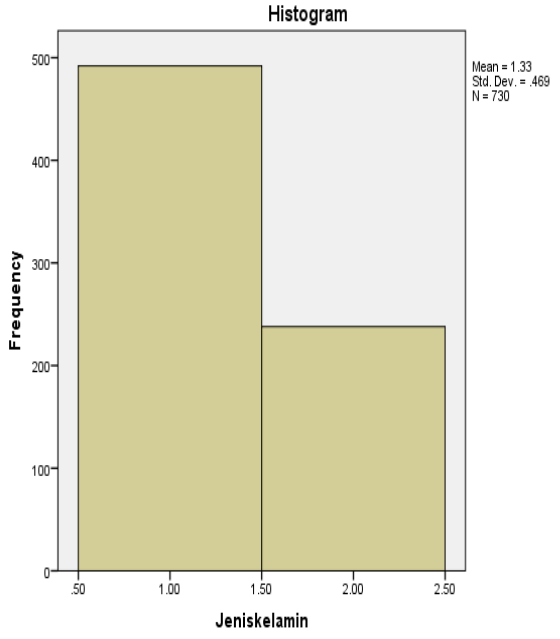

Gambar 2. Histogram Jenis Kelamin

Rumus perhitungan outlier jenis kelamin yaitu $\mathrm{IQR}=\mathrm{Q} 3-\mathrm{Q} 1$. Contoh perhitungan outlier jenis kelamin:

$$
\begin{aligned}
\mathrm{IQR} & =2-1=1 \\
\mathrm{UOF} & =\mathrm{Q} 3+(1.5 \times \mathrm{IQR}) \\
& =2+(1.5 \times 1)=3.5 \\
\mathrm{LOF} & =\mathrm{Q} 1-(1.5 \times \mathrm{IQR}) \\
& =1-(1.5 \times 1)=-0.5
\end{aligned}
$$

Berdasarkan perhitungan batas outlier tidak ditemukan data yang kurang ataupun lebih dari dipersyaratkan berarti keseluruhan data bisa dilanjutkan untuk data jenis kelamin.

3) Transformasi Data

Setelah dilakukan pengujian data outlier maka diperlukan pemberian kode pada masing-masing data seperti jenis kelamin, tipe kamar, asal daerah, metode booking. Transformasi data dilakukan agar data tersebut dapat dilanjutkan ke proses pengolahan data. Contoh proses transformasi data dapat dilihat pada Tabel IV.

TABEL IV

TRANFORMASI DATA

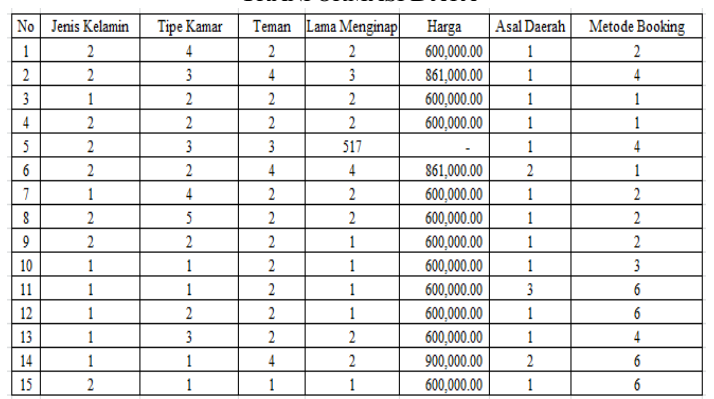

Keterangan :

- $\quad$ Kode untuk Jenis kelamin: Laki-laki = 1 , Perempuan $=2$
- $\quad$ Kode untuk Tipe kamar: DLXT $=1$, $\operatorname{DLX}=2$, GDLX $=3$, JST $=4$, EXEC $=5, \mathrm{ST}=6$,

- $\quad$ Kode asal daerah: $\mathrm{INA}=1, \mathrm{SIN}=2$, $\mathrm{MYA}=3$

- Kode metode booking: Media Putra Mandiri / PUPR $=1$, Cinnamon Hotel $=2$, Traveloka $=3$, Agoda $=4$, Pegipegi $=5$, Individu $=6$, Booking $\cdot \mathrm{com}=7$.

\section{Pengolahan Data}

Langkah-langkah olah dapa penelitian ini disampaikan berurutan sesuai dengan metodologi penelitian. Adapun langkah- langkah proses clustering adalah sebagai berikut:

1) Tahap 1 Menentukan Pusat Cluster (cluster awal )

TABEL V

PUSAT CLUSTER AWAL

Initial Cluster Centers

\begin{tabular}{|l|r|r|r|}
\hline & \multicolumn{3}{|c|}{ Cluster } \\
\cline { 2 - 4 } & \multicolumn{1}{|c|}{1} & \multicolumn{1}{|c|}{2} & \multicolumn{1}{c|}{} \\
\hline Jenis_kelamin & 2.00 & 2.00 & 1.00 \\
Tipe_kamar & 4.00 & 6.00 & 1.00 \\
Teman & .25 & .25 & .25 \\
Lama_menginap & .40 & .40 & .00 \\
Harga & .47 & .55 & .11 \\
Asal_daerah & 1.00 & 1.00 & 1.00 \\
Metode_booking & 7.00 & 1.00 & 2.00 \\
\hline
\end{tabular}

Tabel $\mathrm{V}$ merupakan tampilan pertama atau proses menentukan pusat cluster awal (Initial Cluster Centers) dari vaiabel penginap hotel " $\mathrm{X}$ " sebelum dilakukan iterasi.

\section{2) Tahap 2 Proses Iterasi}

Tahap kedua yaitu memasukkan objek variabel penginap hotel " $X$ " berdasarkan jarak terdekat atau disebut proses iterasi, dengan bantuan paket SPSS versi 20. Maka didapat output sebagai berikut : TABEL VI PRoses Pengulangan

\section{Iteration History}

\begin{tabular}{|l|r|r|r|}
\hline \multirow{2}{*}{ Iteration } & \multicolumn{3}{|c|}{ Change in Cluster Centers } \\
\cline { 2 - 4 } & 1 & \multicolumn{1}{c|}{2} & \multicolumn{1}{c|}{3} \\
\hline 1 & 1.936 & 1.655 & 1.358 \\
2 & .120 & .105 & .034 \\
3 & .000 & .000 & .000 \\
\hline
\end{tabular}

Tabel VI merupakan proses mengubah atau mengacak cluster yang sebelumnya sehingga menjadi lebih tepat dalam mengelompokkan variabel tersebut. Setelah terjadi 3 tahapan iterasi (proses pengulangan) maka selanjutnya akan didapatkan cluster membership. 
3) Tahap 3 Cluster Membership

Pada tahap ini mengelompokkan cluster 1,2,3 selanjutnya akan didapatkan cluster membership dengan bantuan paket program SPSS maka akan didapat output bisa dilihat dalam lampiran.

\section{4) Tahap Cluster Centers}

Pada akhir proses yang dilakukan yaitu jarak yang disesuaikan bersama beberapa objek dalam cluster. Pada metode ini calon pusat cluster awal dipilih secara random dari seluruh observasi selanjutnya akan didapatkan final cluster center dengan bantuan SPSS pada Tabel VII.

TABEL VII

PUSAT AKHIR CLUSTER

Final Cluster Centers

\begin{tabular}{|l|r|r|r|}
\hline \multirow{2}{*}{} & \multicolumn{3}{|c|}{ Cluster } \\
\cline { 2 - 4 } & \multicolumn{1}{|c|}{1} & \multicolumn{1}{|c|}{2} & \multicolumn{1}{c|}{3} \\
\hline Jenis_kelamin & 1.34 & 1.40 & 1.31 \\
Tipe_kamar & 2.44 & 4.76 & 2.20 \\
Teman & .24 & .23 & .28 \\
Lama_menginap & .18 & .30 & .27 \\
Harga & .29 & .42 & .29 \\
Asal_daerah & 1.02 & 1.00 & 1.11 \\
Metode_booking & 5.94 & 2.03 & 2.43 \\
\hline
\end{tabular}

5) Tahap 5 jarak antara pusat cluster final

Pada tahap ini akan dilihat antara jarak pusat cluster akhir dari masing-masing cluster dapat dilihat pada Tabel VIII. TABEL VIII

JARAK ANTARA PUSAT CLUSTER FINAL Distances between Final Cluster Centers

\begin{tabular}{|l|l|l|l|}
\hline Cluster & 1 & 2 & 3 \\
\hline 1 & & 4.554 & 3.517 \\
2 & 4.554 & & 2.600 \\
3 & 3.517 & 2.600 & \\
\hline
\end{tabular}

6) Tahap 6 propilisasi.

Tahapan ini akan meilihat sifat atau profil serta kecenderungan yang ada dengan interpretasi dari cluster yang terbentuk. Tahapan kedua yaitu non hirarkhi bermanfaat untuk propilisasi untuk melihat kecenderungan yang ada. Hasil dapat dilihat pada Tabel IX.

TABEL IX
JUMLAH CLUSTER
Number of Cases in each
Cluster
\begin{tabular}{|ll|r|}
\hline Cluster & 1 & 238.000 \\
& 2 & 294.000 \\
& 3 & 193.000 \\
Valid & & 725.000 \\
Missing & & .000 \\
\hline
\end{tabular}

Berdasarkan Tabel IX dapat dilihat responden terbanyak ada di cluster ke-2 yaitu 294 sedangkan responden paling sedikit terdapat pada cluster ke-3 yaitu 193 dan cluster ke-1 238 dengan tidak ada data yang hilang atau missing. Hasil menunjukkan bahwa semua kasus responden sejumlah 725 data lengkap tanpa ada yang hilang.

\section{PEMBAHASAN}

\section{A. Analisis Clustering}

Pengolahan data dari variabel jenis kelamin, tipe kamar, teman, lama menginap, harga, asal daerah, metode booking menghasilkan 3 cluster. Cluster ke-1 dari hasil perhitungan didapatkan hasil yang menginap di hotel " $X$ " dari tahun 2018 yaitu kebanyakan orang berjenis kelamin Perempuan dari pesanan kamar, kebanyakan tipe kamar DLXK, dan membawa teman berjumlah 2 orang, menginap selama 2 hari, dari harga Rp.670.225, mayoritas pelanggan di hotel " $X$ " berkewarganegaraan Indonesia, pemesanan dilakukan melalui media daring seperti Pegipegi. Oleh karena itu cluster ini dinamai online-low customer, sebab dilihat dari pemesanan kamar dan harga yang cukup murah bagi kalangan menengah ke bawah.

Cluster ke-2 dinamai medium customer, pelanggan dalam kelompok ini adalah orang-orang yang memiliki pendapatan sedang, kebanyakan yang menginap dan memesan kamar di hotel " $X$ " adalah laki-laki dengan tipe kamar JST, rata-rata membawa teman 2 orang dan menginap selama 3 hari dari harga Rp.790.000. mayoritas dalam cluster ini adalah berkewarganegaraan Indonesia, pemesanan dilakukan melalui Hotel " $\mathrm{X}$ " baik secara langsung maupun media daring.

Cluster ke-3 ini hampir sama dengan cluster ke-1 yang membedakan cluster ke3 ini yaitu dari segi pemesanan hotel, cluster ini dinamai offlinemanual customer karena pelanggan dalam kelompok ini merupakan cluster terakhir yang secara langsung datang ke hotel " $\mathrm{X}$ " untuk memesan kamar tanpa melalui media lain seperti cluster ke-1 yang menggunakan pemesanan daring. kebanyakan orang yang menginap berjenis kelamin laki-laki dari pesanan kamar dengan tipe kamar DLXK, dan membawa teman berjumlah 2 orang, menginap selama 2 hari, dari harga Rp.670.225, pelanggan ini adalah kalangan rendah, mayoritas pelanggan di hotel " $X$ " berkewarganegaraan Indonesia.

Dari analisis tersebut dapat dihasilkan, yaitu terbentuknya 3 cluster di hotel " $\mathrm{X}$ " mempunyai karakteristik yang berbeda, perbedaan tersebut dilakukan karena perusahaan ingin memberikan pelayanan yang terbaik bagi konsumen. Seperti di cluster ke-1 perusahaan memberikan kemudahan pemesanan kamar hotel dengan disediakannya 
fasilitas seperti pemesanan daring, akan tetapi langkah yang harus diambil perusahaan adalah semakin memperbanyak channel pemesanan daring dan memperbanyak mekanisme pembayaran daring. Begitu pun dengan cluster ke2 dan ke-3, jika cluster tersebut melakukan pemesanan secara langsung, maka perusahaan harus memberikan pelayanan yang baik pula kepada konsumen, seperti menggunakan tata krama yang baik, kata-kata yang sopan dan tidak menampilkan wajah yang tampak kesal pada saat pemesanan hotel, memberikan informasi pemesanan hotel secara rinci dari mulai harga, tipe kamar ataupun kebutuhan lain bagi konsumen, pelayanan yang diberikan tidak membedakan jenis pesanan misalnya pada saat konsumen memesan tipe kamar yang berbeda dengan jenis yang berbeda antara, JST dan DLXK sekalipun harganya berbeda tetapi pelayanan harus tetap memberikan kenyamanan bagi konsumen.

\section{B. Pembahasan}

Produk Hotel merupakan jenis produk jasa. Produk jasa ini diharapkan dapat memberikan manfaat bagi konsumen yaitu sebagai tempat yang nyaman untuk menginap, memenuhi kebutuhan konsumen, dan dapat memuaskan konsumen. Konsumen tidak membeli produk berupa barang melainkan jasa pelayanan. Kamar merupakan produk utama Hotel " $X$ " yang menjadi tujuan pemasaran diantara produk yang lain, jasa menggunakan kamar untuk bermalam terbilang cukup potensial tergantung pada letak dan lokasi dari pariwisata itu sendiri, dan Hotel "X" ini terbilang berlokasi yang cukup strategis yaitu dekat dengan tempat wisata seperti Farmhouse, Cikole, gunung Tangkuban Perahu. dengan memberikan jasa menginap yang disertai dengan pelayanan yang baik dan kelengkapan fasilitas yang menunjang kesempurnaan liburan bagi tamu dan hotel "X".

Kondisi ideal kamar cluster 1 dan 3 kondisi fisik kamar tidur yang ideal adalah yang berbentuk persegi/bujur sangkar, dengan ukuran 28 inci, dengan atap rata (tidak miring), bersih, rapi, dan sirkulasi udara lancar. Tempat tidur tidak boleh diletakkan berhadapan langsung dengan pintu kamar. Posisinya juga tidak boleh membelakangi atau bersandar pada jendela (harus dinding masif, tidak boleh membelakangi sudut kamar), serta jangan berhadapan langsung dengan kloset, kondisi pintunya sangat rapi catnya pun masih mengilat, terdapat fasilitas seperti tempat tidur, kamar mandi, telepon, wifi, AC, kursi, meja, lemari baju, dan televisi dengan ukuran 32 inch, terdapat resto yang menghidangkan makanan untuk makan pagi, makan siang, dan makan malam. Dengan fasilitas tersebut memberikan kenyamanan bagi konsumen hotel sehingga menjadi acuan bagi perusahaan untuk lebih meningkatkan fasilitas hotel demi kepuasan konsumen.

Cluster ke-2 dengan fasilitas seperti tempat tidur, meja, kursi, televisi berukuran 47 inch, lemari baju, kamar mandi, telepon, AC, akses wifi gratis, Terdapat resto yang menghidangkan makanan untuk makan pagi, makan siang, dan makan malam dan yang membedakannya dari cluster ke-1 yaitu dari segi ruangan cukup luas kisaran 40 meter, dan fasilitas lebih unggul dari cluster ke-1 dan ke-3 hal tersebut memberikan gambaran bagi perusahaan untuk lebih meningkatkan kualitas kamar dan pelayanan hotel "X" supaya memberikan kepuasan bagi konsumen hotel.

Tempat hotel " $\mathrm{X}$ " sudah cukup strategis karena tidak jauh jaraknya dari tempat wisata seperti Farmhouse, gunung Tangkuban Perahu, Cikole, alam Lembang, dan dari perkantoran serta pusat perbelanjaan. Jadi tempat hotel " $\mathrm{X}$ " sudah cukup strategis, dan dari setiap cluster nya pun sudah tepat seperti cluster 1,2 dan cluster 3 yang dimana tata letak hotelnya pun berada pinggiran jalan, pinggiran kota dan mal, oleh karena itu cocok bagi setiap cluster yang terbentuk dalam karakteristik konsumen yang menginap di hotel "X", karena berada di wilayah sasaran pasarnya yang merupakan alternatif tepat bagi para tamu yang berkunjung di wilayah hotel "X" dan merupakan wilayah pasarnya yang terletak di Jalan Setiabudi Bandung, Jawa Barat.

Promosi merupakan aktivitas pemasaran yang berusaha menyebarkan informasi, mempengaruhi/membujuk, dan mengingatkan pasar sasaran atas perusahaan dan produknya agar bersedia menerima, membeli dan loyal pada produk yang ditawarkan [6]. Untuk menarik minat tamu agar mau menginap di hotel sebaiknya menyiapkan suatu promosi melalui iklan dan promosi yang baik agar penyebaran informasi tentang komposisi produk hotel " $\mathrm{X}$ " tersampaikan kepada target pasar supaya lebih menarik minat para konsumen, seperti cluster 1 untuk pemesanan melalui media daring. Promosinya berupa penayangan video iklan hotel dan berisi tentang fasilitas, harga dan proses pelayanan kamar serta lebih menonjolkan kelebihan dari Hotel "X". Seperti cluster 2 dan 3 untuk pemesan yang datang secara langsung di sediakan brosur yang berisikan menu tentang fasilitas, harga, proses pelayanan, dan menempatkan resepsionis yang menyambut tamu sekaligus memberikan informasi tentang hotel beserta pelayanannya dan tidak lupa untuk menonjolkan kelebihan dari hotel " $\mathrm{X}$ ". Hal ini 
bertujuan untuk mendapatkan konsumen baru dan menjaga kesetiaan konsumen, untuk menjaga kestabilan penjualan ketika terjadi lesu pasar, membedakan serta mengunggulkan produk dibanding produk pesaing, membentuk citra produk di mata konsumen sesuai dengan yang diinginkan. mengubah tingkah laku dan pendapat konsumen.

Proses merupakan metode pengoperasian atau serangkaian tindakan tertentu, yang umumnya berupa langkah-langkah yang diperlukan dalam suatu urutan yang telah ditetapkan [7]. Seluruh aktivitas kerja proses adalah yang terkait prosedur, tugas, jadwal, mekanisme, aktivitas dan rutinitas dengan apa produk disalurkan ke pelanggan. Seperti cluster ke-1 proses pemesanannya melalui media daring, jadi cara meningkatkan pelayanan melalui pemesanan daring disarankan dalam aplikasi pelayanannya di sediakan pengiklanan tentang proses pelayanan, dan informasi tentang hotel " $X$ " agar para konsumen yang ingin memesan mengerti tentang pelayanan di hotel dan supaya lebih menarik di perlihatkan juga tentang kelebihan dari pelayanan hotel. Cluster ke-2 dan ke-3 proses pemesanannya sama yang secara langsung datang ke hotel " $\mathrm{X}$ " tanpa melalui media daring dan cara meningkatkan pelayanannya yaitu dengan cara memberikan informasi tentang hotel "X", menyambut tamu dengan baik, sopan dan ramah tidak berbahasa kasar, memberikan pelatihan untuk keterampilan dalam setiap bidangnya, di utamakan bagian pekerja yang berinteraksi langsung pada konsumen.

Bukti Fisik merupakan petunjuk visual atau berwujud lainnya yang memberi bukti atas kualitas jasa [8]. Hotel "X" merupakan sebuah resor dengan bangunan menarik karena desain interiornya yang unik, yaitu yang tampak kokoh, fasilitas bangunan yang lengkap, tata pencahayaan yang baik dan tata ruangnya juga bagus, menarik dan enak di pandang, seperti yang ada di cluster 1,2 dan 3 suasana bersih dan asri, mampu mengikat para tamu yang menginap di hotel " $X$ " yang dimana hotel " $X$ " ini mempunyai kamar berjumlah 50 kamar dan memberikan ruangan bagus dalam setiap kamar. Dan saat ini Hotel "X" juga tengah dalam proses penambahan kamar yaitu 5 kamar dan akan memperbaharui ruangan kamar dengan tujuan semakin memper cantik kondisi fisik bangunan hotel " $\mathrm{X}$ " dan memberikan kenyamanan bagi para penginap di hotel " $X$ ".

\section{KESIMPULAN}

Kesimpulan yang dapat diambil berdasarkan hasil pembahasan adalah :

1. Kesimpulan yang diambil berdasarkan hasil pembahasan dari penelitian bahwa variabel
Jurnal Media

Teknik dan

Sistem Industri

yang digunakan dalam pembentuk clustering konsumen yaitu, Jenis Kelamin, Tipe Kamar yang dipesan, Jumlah teman, Lama menginap, Harga kamar yang di pesan, Kewarganegaraan, Metode Booking.

2. Penelitian ini memperoleh 3 cluster. Cluster pertama merupakan cluster yang sering memesan kamar ekonomis dan memesan secara daring disebut online-low customer. Cluster ke-2 bernama medium customer yaitu cluster konsumen yang memesan kamar kelas menengah, dan cluster ke-3 yang mirip dengan cluster ke-1 tapi memesan melalui media selain daring yaitu offline-manual customer.

\section{REFERENSI}

[1] I. Sidik, "Pariwisata Setoran Terbesar Kota Bandung - Travelounge Indonesia," travelounge, 2018. [Online]. Available: https://travelounge.co/pariwisata-setoran-terbesarkota-bandung/. [Accessed: 11-May-2020].

[2] I. Masrofah and B. E. Putro, "Clustering of the water characteristics of the Cirata reservoir using the $\mathrm{k}$ means clustering method," in the 5Th International Conference on Industrial, Mechanical, Electrical, and Chemical Engineering 2019 (Icimece 2019), 2020, vol. 2217, p. 030010.

[3] Yulia Darmi and Agus Setiawan, "Penerapan Metode Clustering K-Means Dalam Pengelompokan Penjualan Produk," J. Media Infotama, vol. 12, no. 2, 2016.

[4] R. Setiawan, "Penerapan Data Mining Menggunakan Algoritma K-Means Clustering Untuk Menentukan Strategi Promosi Mahasiswa Baru ( Studi Kasus : Politeknik Lp3i Jakarta )," J. Lentera Ict, vol. 3, no. 1, pp. 76-92, 2016.

[5] W. Purba, S. Tamba, and J. Saragih, "The effect of mining data k-means clustering toward students profile model drop out potential," in Journal of Physics: Conference Series, 2018, vol. 1007, no. 1.

[6] C. A. Selang, P. Bauran Pemasaran, and C. A. Selang Fakultas Ekonomi Jurusan Manajemen Universitas Sam Ratulangi Manado, "BAURAN PEMASARAN (MARKETING MIX) PENGARUHNYA TERHADAP LOYALITAS KONSUMEN PADA FRESH MART BAHU MALL MANADO," $J$. EMBA, vol. 71, no. 3, pp. 71-80, Jun. 2013.

[7] N. Nelly, "KOMPONEN MANAJEMEN JASA TERPADU TERHADAP KEPUASAN NASABAH TABUNGAN PADA PT. BANK DANAMON INDONESIA, TB CABANG MESJID LAMA PALEMBANG," J. Ilm. Ekon. Glob. Masa Kini, vol. 7, no. 1, pp. 13-17, Jul. 2016.

[8] K. W. Bank, V. Jakarta, M. Program, and P. M. Manajemen, "Pengaruh Price, People, Process, Dan Physical Evidence Terhadap Brand Image," Mercu Buana University, 2014. 